\title{
Preliminary Report on the Fourth National Nutrition and Health Survey July - August, 1995
}

P. Ramanujam' and P. Nestel ${ }^{1}$

The Ceylon Journal of Medical Science 1997; 40: 13-24

\section{Summary}

The Fourth Sri Lanka Nutrition and Health Survey (NHS4), a nationally representative survey conducted between July and August 1995, provides information on the nutrition status of Sri Lankan children between the age of 3 and 60 months at the national, provincial, and sector (urban/rural) levels. Overall, 20 percent of children were stunted, 33 percent were underweight, and 13 percent were wasted. The prevalence of stunting was significantly higher in the Central province than elsewhere. Stunting and underweight were higher in the estates than in rural areas; they were also higher in the rural areas than in urban areas. Chronic undernutrition was associated with a number of social and economic variables reflecting that children from better-off households were less likely to be undernourished. A comparison of the data for all four NHSs indicates that there has not been any change in the nutrition status of children between 1993 and 1995.

Thirty three percent of mothers and 36 percent of fathers had chronic energy deficiency and were undernourished. Undernutrition was greatest in the Central province and in the estate areas and, not unexpectedly, more prevalent among the bottom two income quartiles. These results are consistent with those from NHS3.

Data on reported nightblindess among children age two to five years suggest that clinical vitamin A deficiency is not a 'public.health problem in Sri Lanka, with 0.5 percent cases reported. This result is also consistent with that from NHS3.

Eighty two.percent of mothers had heard about iodized salt but just under one-half of these do not use iodized salt. Among the mothers that do use iodized salt, 44 percent do so to prevent goitre, a further 46 percent do so for health reasons although they do not specify goitre, and the remainder cite other reasons. Mothers in the North Western and North Central provinces appeared to be more aware of the broader need for iodine, in that they were more likely to cite health reasons, while mothers in the other provinces were more likely to state that iodized salt prevents goitre. Clearly, a greater effort is needed to ensure that households have access to and use iodized salt.

Chronic energy deficiency (as indicated by a $\mathrm{BMI}<18.5)$ is highest in the estate sector $(59 \%$ for mothers and $50 \%$ for fathers) and lowest in the urban areas (21\% for mothers, $28 \%$ for fathers). Prevalence of energy deficiency was high in the Central, Southern and North-Central provinces, and was associated with decreasing income.

\section{Introduction}

This report presents the nutrition results of the Fourth National Nutrition and Health Survey (NHS4), which was conducted between July and August 1995. A full report of this survey will be made available once data from all four National Nutrition and Health Surveys are analyzed -together.

\section{Population and Methods}

Details of the sample selection were given in the First National Nutrition and Health Survey (1). Briefly, the survey represent all provinces except the Northern and Eastern provinces, and all sectors, viz., urban, rural, and estate sectors. Data were collected on household demographics as well as the health and nutrition status of mothers, fathers and children.

Nutritional status is determined using measures of height and weight in combination with age, expressed as Z-scores (2). Three different indicators of nutritional status are used. Stunting, (HAZ<-2), a failure to grow adequately in height in relation to age, reflects 
past or chronic undernutrition; resulting from an inadequate intake of food over a period of time and/or from chronic illness. Wasting, (WHZ<-2), a failure to gain weight in relation to height, reflects recent or acute undernutrition; resulting from a recent failure to receive adequate nutrition and/or from acute illness, in particular diarrhoea. Underweight (WAZ<-2), a low weight in relation to age, can be due to either chronic or acute undernutrition.

\section{Results}

1. Levels of undernutrition in children age 3 to 59 months

The fourth NHS shows that 20 percent of Sri Lankan children age 3 to 60 months were stunted, 33 percent were underweight, and 13 percent were wasted (Table 1) which was 9, 15 and 6 times respectively, the level expected in a well nourished healthy population. (In a healthy well nourished population 2.2 percent of children are expected to be moderately undernourished and 0.1 severely so). The data also showed that 5 percent of children were severely stunted, 6 percent were severely underweight, and 1 percent were severely wasted (i.e. below - 3 SD of the reference median) (Table 1). In a healthy, well nourished population only one in 1,000 children is expected to be severely undernourished. The data for Sri Lanka indicate that the level of severe stunting and severe underweight were extremely high at 51 and 57 times, respectively, that expected in a healthy, well nourished population while that for wasting was 9 times higher.

Using the Waterlow classification, which is a composite measure of nurtitional status, 4 percent of children were both stunted and wasted, reflecting the severest type of undernutrition, 17 percent were stunted only, 10 percent were wasted only, and 70 percent were neither stunted or wasted (Table 2). The nutrition status of children was worse in the Central region where most of the estate children live.

\section{Undernutrition in relation to geographic characteristics}

There were noticeable provincial differences in the prevalence of stunting $(p<0.001)$ and underweight $(p<0.001)$ but not wasting (Table 2). Stunting and underweight were highest in

Table 1

Percentage of children age 3 to 60 months moderately and severely stunted, underweight, and wasted by province and sector

\begin{tabular}{|c|c|c|c|c|c|c|c|}
\hline \multirow[b]{3}{*}{ OVERALL } & \multicolumn{2}{|c|}{ Stunting } & \multicolumn{2}{|c|}{ Underweight } & \multicolumn{2}{|c|}{ Wasting } & \multirow{3}{*}{$\begin{array}{r}\text { No. } \\
2782\end{array}$} \\
\hline & Moderate & Severe & Moderate & Severe & Moderate & Severe & \\
\hline & 15.3 & 5.1 & 27.2 & 5.7 & 12.4 & 0.9 & \\
\hline \multicolumn{8}{|l|}{ PROVINCE } \\
\hline Western & 10.4 & 2.9 & 20.3 & 4.4 & 9.6 & 1.8 & 663 \\
\hline Central & 22.1 & 10.7 & 30.3 & 9.9 & 14.4 & 0.9 & 542 \\
\hline Southern & 15.7 & 2.8 & 28.9 & 3.9 & 11.6 & 0.9 & 216 \\
\hline North Western & 12.5 & 3.4 & 26.2 & 5.2 & 14.2 & 1.0 & 296 \\
\hline North Central & 11.7 & 4.5 & 26.5 & 3.6 & 12.4 & 0.7 & 309 \\
\hline Uva & 17.0 & 5.5 & 28.5 & 5.8 & 10.2 & 0 & 365 \\
\hline Sabaragamuwa & 17.4 & 3.8 & 33.8 & 5.1 & 15.6 & 0.5 & 391 \\
\hline \multicolumn{8}{|l|}{ SECTOR } \\
\hline Urban & 10.7 & 2.4 & 21.9 & 3.9 & 11.3 & 1.3 & 1359 \\
\hline Rural & 15.3 & 4.4 & 28.7 & 5.9 & 14.2 & 0.7 & 991 \\
\hline Estate & 29.9 & 15.3 & 40.6 & 10.9 & 11.9 & 0.2 & 432 \\
\hline
\end{tabular}


Table 2

Waterlow classification of nutritional status by province and sector

\begin{tabular}{|c|c|c|c|c|c|c|}
\hline OVERALL & $\begin{array}{c}\text { Stunted } \\
\text { and } \\
\text { wasted } \\
3.8\end{array}$ & $\begin{array}{c}\text { Stunted } \\
\text { only }\end{array}$ & $\begin{array}{c}\text { Wasted } \\
\text { only } \\
9.6\end{array}$ & $\begin{array}{c}\text { Not Stunted } \\
\text { or } \\
\text { wasted } \\
70.0\end{array}$ & $\begin{array}{c}n \\
2753\end{array}$ & \\
\hline \multicolumn{7}{|l|}{ PROVINCE } \\
\hline Western & 2.9 & 10.5 & 8.5 & 78.5 & 657 & \\
\hline Central & 6.6 & 26.1 & 8.8 & 58.5 & 532 & \\
\hline Southern & 2.8 & 15.9 & 9.8 & 71.5 & 214 & \\
\hline North Western & 3.7 & 12.2 & 11.6 & 72.4 & 294 & \\
\hline North Central & 2.6 & 13.4 & 10.4 & 73.6 & 307 & \\
\hline Uva & 2.5 & 19.9 & 7.8 & 69.8 & 361 & \\
\hline Sabaragamuwa & 4.1 & 17.3 & 12.1 & 66.5 & 388 & $p<0.001$ \\
\hline \multicolumn{7}{|l|}{ SECTOR } \\
\hline Urban & 3.0 & 10.1 & 9.7 & 77.2 & 1343 & \\
\hline Rural & 3.9 & 15.7 & 11.1 & 69.3 & 982 & \\
\hline Estate & 6.1 & 39.3 & 6.1 & 48.6 & 428 & $p<0.001$ \\
\hline
\end{tabular}

the (Table 1), Central province where 33 and 40 percent, respectively, of the children were stunted and underweight and lowest in the Western province where 13 and 25 percent of children were stunted and underweight, respectively.

Stunting and underweight were also associated with sector, that is, whether children lived in urban, rural, or estate areas. The estates had close to 3.5 times more ( 45 versus 13 percent) stunted children and twice as many underweight children ( 51 versus 26 percent) than urban areas. Similarly, there were 33 percent more stunted ( 20 versus 13 percent) and 25 percent more underweight ( 35 versus 26 percent) children in rural areas than in urban ones (Table 1).

Undernutrition in relation to social and economic characteristics

Social and economic indicators associated with stunting, underweight, and wasting are presented in Table 3.a and 3.b Children were more likely to be chronically undernourished if they came from households that were ethnically Tamil. Most of the Tamils in the sample studied were in the estate sectors In addition, children whose family did not live in a single house and those from homes without a flush toilet; piped water to the house, motorized transport, and a high household score* were more likely to be chronically undernourished than children from households with the above items. Chronic undernutrition was also positively associated with the child's mother having a lower level or no education; being from a household in the bottom two income quartiles; and living more than one kilometer from a health clinic.

More children from households receiving welfare (Samurdhi or Janasaviya) and receiving triposha regularly were chronically undernourished compared with other children (Table 3.b). Chronic undernutrition among children was also associated with the household consuming fewer than three meals a day; households in which dinner was the main meal of the day; and households in which milk, dried fish, or meat were not taken in the previous 7 days and eggs were eaten less than twice in the preceding week.

Acute undernutrition was associated with children from households having a low or zero

"Items owned by the household were each given a score of one. They included a radio, cassette recorder, wall clock, television set, sewing machine, electric/gas cooker, refrigerator and telephone. 
Table 3.a

Percentage of children age 3 to 60 months stunted, underweight, and wasted by social and economic factors

\begin{tabular}{|c|c|c|c|c|}
\hline & Stunted & Underweight & Wasted & No. \\
\hline $\begin{array}{l}\text { ETHNIC GROUP } \\
\text { Sinhalese }\end{array}$ & \multicolumn{2}{|c|}{ ETHNIC GROUP } & 14.3 & 1796 \\
\hline Tamil & 39.1 & 46.5 & 12.0 & 535 \\
\hline \multirow[t]{2}{*}{ Muslim/other } & 16.0 & 25.7 & 11.5 & 408 \\
\hline & $p<0.001$ & $p<0.001$ & ns & \\
\hline \multicolumn{5}{|l|}{ TYPE OF HOUSE } \\
\hline Single & 16.3 & 30.1 & 13.4 & 2016 \\
\hline Other & 31.9 & 40.7 & 13.5 & 712 \\
\hline \multicolumn{5}{|l|}{ TYPE OF TOILET } \\
\hline None & 40.0 & 49.4 & 12.8 & 398 \\
\hline Own Flush & 14.2 & 27.4 & 13.1 & 1650 \\
\hline Share Flush & 22.7 & 33.5 & 14.6 & 260 \\
\hline Own Other & 23.0 & 36.5 & 14.2 & 394 \\
\hline \multirow[t]{2}{*}{ Share Other } & 50.0 & 78.9 & 22.2 & 18 \\
\hline & $\mathrm{p}<0.001$ & $\mathrm{p}<0.001$ & ns & \\
\hline \multicolumn{5}{|c|}{ SOURCE OF DRINKING WATER } \\
\hline Protected Well & 19.3 & 34.0 & 13.5 & 855 \\
\hline Unprotected Well & 22.5 & 40.8 & 16.8 & 298 \\
\hline Pipe & 9.8 & 18.9 & 10.6 & 554 \\
\hline Public Tap & 25.9 & 37.2 & 13.5 & 907 \\
\hline \multirow[t]{2}{*}{ Other } & 29.8 & 36.0 & 16.8 & 113 \\
\hline & $\mathrm{p}<0.001$ & $\mathrm{p}<0.001$ & ns & \\
\hline \multicolumn{5}{|c|}{ TYPE OF TRANSPORT OWN } \\
\hline None & 24.4 & 36.5 & 14.1 & 1853 \\
\hline Bicycle & 14.2 & 30.8 & 12.2 & 523 \\
\hline Motor Bike & 10.1 & 20.4 & 11.4 & 228 \\
\hline \multirow{2}{*}{ Car/Van } & 5.7 & 10.4 & 11.4 & 123 \\
\hline & $p<0.001$ & $p<0.001$ & ns & \\
\hline \multicolumn{5}{|c|}{ HOUSEHOLD SCORE* } \\
\hline None & 41.4 & 53.2 & 16.9 & 372 \\
\hline 1 & 27.0 & 39.3 & 14.0 & 392 \\
\hline 2 & 24.0 & 39.3 & 17.1 & 598 \\
\hline 3 & 16.7 & 29.6 & 11.6 & 422 \\
\hline 4 & 10.0 & 22.2 & 9.5 & 328 \\
\hline \multirow{2}{*}{$5+$} & 7.9 & 18.2 & 10.9 & 607 \\
\hline & $\mathrm{p}<0.001$ & $p<0.001$ & $p<0.002$ & \\
\hline \multicolumn{5}{|c|}{ MOTHER'S EDUCATION } \\
\hline None & 41.6 & 46.5 & 10.8 & 114 \\
\hline Grade $1-5$ & 37.2 & 42.9 & 13.8 & 396 \\
\hline Grade 6-8 & 17.9 & 34.0 & 12.0 & 403 \\
\hline Grade $9-10$ & 16.0 & 29.5 & 15.1 & 495 \\
\hline GCE O/L & 12.4 & 25.1 & 15.1 & $\begin{array}{l}470 \\
470-12 x-10\end{array}$ \\
\hline \multirow[t]{2}{*}{ Higher } & 7.9 & 18.3 & 12.2 & 333 \\
\hline & $\mathrm{p}<0.001$ & $\mathrm{p}<0.001$ & ns & \\
\hline \multicolumn{5}{|l|}{ INCOME } \\
\hline Lowest quartile & 26.2 & 43.0 & 16.3 & 711 \\
\hline Second quartile & 26.4 & 39.0 & 15.2 & 673 \\
\hline & 20.4 & 29.9 & 11.4 & 673 \\
\hline \multirow{2}{*}{ Highest quartile } & 8.3 & 19.4 & 10.8 & 676 \\
\hline & $p<0.001$ & $p<0.001$ & $p<0.005$ & \\
\hline \multicolumn{5}{|c|}{ DISTANCE TO CLINIC } \\
\hline$<1 \mathrm{~km}$ & 15.2 & 30.5 & 14.2 & 665 \\
\hline $1-2 \mathrm{~km}$ & 19.1 & 32.3 & 12.7 & 765 \\
\hline \multirow[t]{2}{*}{$>2 \mathrm{~km}$} & 22.3 & 30.6 & 13.1 & 736 \\
\hline & $p<0.001$ & ns & ns & \\
\hline
\end{tabular}

- Items were assigned a score of one if they were owned, and included raido/cassette, wall clock, T.V., sewing machine, electric/gas cooker, refrigerator and telephone. 
Table 3.b

Percentage of children age 3 to 60 months stunted, underweight, and wasted by social and economic factors

\begin{tabular}{|c|c|c|c|c|}
\hline & Stunted & Underweight & Wasted & No. \\
\hline \multicolumn{5}{|c|}{ SAMURDHI/JANASAVIYA } \\
\hline No & 19.3 & 30.8 & 12.5 & 2018 \\
\hline \multirow[t]{2}{*}{ Yes } & 23.9 & 38.9 & 16.0 & 689 \\
\hline & $p<0.02$ & $p<0.001$ & $p<0.05$ & \\
\hline \multicolumn{5}{|c|}{ RECEIVED TRIPOSHA } \\
\hline No & 17.7 & 29.7 & 12.7 & 1916 \\
\hline Regularly & 35.1 & 46.8 & 14.7 & 268 \\
\hline \multirow[t]{2}{*}{ Not Regularly } & 21.6 & 37.9 & 15.0 & 504 \\
\hline & $\mathrm{p}<0.001$ & $p<0.001$ & ns & \\
\hline \multicolumn{5}{|c|}{ NUMBER OF MEALS/DAY } \\
\hline$<3$ & 25.4 & 36.8 & 13.3 & 1400 \\
\hline \multirow[t]{2}{*}{3} & 15.1 & 28.8 & 13.3 & 1347 \\
\hline & $p<0.001$ & $\mathrm{p}<0.001$ & ns & \\
\hline \multicolumn{5}{|l|}{ MAIN MEAL } \\
\hline Breakfast & 10.2 & 20.8 & 10.4 & 283 \\
\hline Lunch & 17.8 & 31.2 & 13.9 & 1548 \\
\hline \multirow[t]{2}{*}{ Dinner } & 27.9 & 39.6 & 13.6 & 931 \\
\hline & $p<0.001$ & $p<0.001$ & ns & \\
\hline \multicolumn{5}{|c|}{ NO. TIMES HH* DRANK } \\
\hline \multicolumn{5}{|c|}{ MILK LAST WEEK } \\
\hline None & 29.2 & 42.9 & 14.1 & 619 \\
\hline $1-7$ times & 19.8 & 32.0 & 13.6 & 1512 \\
\hline $8-14$ times & 12.4 & 24.1 & 11.7 & 547 \\
\hline \multirow[t]{2}{*}{$15+$ times } & 15.4 & 32.1 & 17.9 & 78 \\
\hline & $p<0.001$ & $p<0.001$ & ns & \\
\hline \multirow{2}{*}{\multicolumn{5}{|c|}{$\begin{array}{l}\text { NO. TIMES HH ATE DRIED } \\
\text { FISH LAST WEEK }\end{array}$}} \\
\hline & & & & \\
\hline 0 & 27.0 & 36.3 & 12.9 & 259 \\
\hline 1 & 18.8 & 30.0 & 13.5 & 298 \\
\hline 2 & 17.4 & 32.6 & 14.4 & 547 \\
\hline 3 & 19.6 & 33.5 & 15.1 & 545 \\
\hline 4 & 18.5 & 29.1 & 12.2 & 438 \\
\hline \multirow[t]{2}{*}{$5+$ Times } & 22.5 & 35.2 & 12.3 & 666 \\
\hline & $p<0.02$ & ns & ns & \\
\hline \multirow{2}{*}{\multicolumn{5}{|c|}{$\begin{array}{l}\text { NO. TIMES HH ATE } \\
\text { MEAT LAST WEEK }\end{array}$}} \\
\hline & & & & \\
\hline 0 & 25.3 & 39.2 & 14.7 & 1259 \\
\hline 1 & 19.2 & 31.0 & 12.6 & 730 \\
\hline 2 & 12.5 & 25.8 & 13.9 & 361 \\
\hline 3 & 14.8 & 24.0 & 12.2 & 183 \\
\hline 4 & 11.2 & 21.2 & 12.2 & 98 \\
\hline \multirow[t]{2}{*}{$5+$ Times } & 15.7 & 21.3 & .5 .8 & 121 \\
\hline & $p<0.001$ & $p<0.001$ & ns & \\
\hline \multirow{2}{*}{\multicolumn{5}{|c|}{$\begin{array}{l}\text { NO. TIMES HH ATE } \\
\text { EGGS LAST WEEK }\end{array}$}} \\
\hline & & & & \\
\hline 0 & 25.8 & 40.0 & 13.2 & 550 \\
\hline 1 & 23.5 & 37.2 & 15.3 & 620 \\
\hline 2 & 18.8 & 31.2 & 13.4 & 808 \\
\hline 3 & 16.9 & 27.9 & 13.7 & 473 \\
\hline 4 & 11.3 & 22.1 & 9.9 & 151 \\
\hline \multirow{2}{*}{$5+$ Times } & 16.8 & 27.2 & 9.1 & 155 \\
\hline & $\mathrm{p}<0.001$ & $p<0.001$ & ns & \\
\hline
\end{tabular}

Vol. 40 No. 1, June 1997 
household score, being in the bottom two income quartiles, and the household being in a welfare program.

Many of the above social and economic factors, however, not only interact with each other but also with province and sector, i.e. they reflect the same social and economic status. Items such as television sets, refrigerators, cookers would not be seen in areas without gas or electricity supply.

\section{Undernutrition and biological factors}

More boys were acutely undernourished than girls (Table 4). The reasons for this will be examined in further analyses. Children born with a low birth weight were more likely to be chronically and acutely undernourished than other children indicating that these children failed to compensate for the nutritional insult inflicted during foetal growth. The fact that a

Table 4

Percentage of children age 3 to 60 months stunted, underweight, and wasted by food and health factors

\begin{tabular}{|c|c|c|c|c|}
\hline & Stunted & Underweight & Wasted & No. \\
\hline \multicolumn{5}{|l|}{ SEX } \\
\hline Male & 18.8 & 31.2 & 15.4 & 1114 \\
\hline \multirow[t]{2}{*}{ Female } & 18.3 & 30.5 & 11.9 & 1112 \\
\hline & ns & ns & $\mathrm{p}<0.02$ & \\
\hline \multicolumn{5}{|c|}{ BIRTH WEIGHT } \\
\hline Low & 29.2 & 46.9 & 21.0 & 677 \\
\hline Normal & 15.0 & 25.2 & 10.2 & 1590 \\
\hline \multirow{2}{*}{ Unknown } & 25.6 & 38.4 & 13.1 & 515 \\
\hline & $p<0.001$ & $p<0.001$ & $p<0.001$ & \\
\hline \multicolumn{5}{|c|}{ DIARRHOEA } \\
\hline Yes & 38.5 & 45.1 & 5.8 & 52 \\
\hline \multirow[t]{2}{*}{ No } & 20.2 & 32.9 & 13.5 & 2694 \\
\hline & $p<0.002$ & ns & ns & \\
\hline \multicolumn{5}{|l|}{ FEVER } \\
\hline Yes & 28.1 & 37.9 & 13.1 & 493 \\
\hline \multirow[t]{2}{*}{ No } & 18.8 & 32.0 & 13.4 & 2259 \\
\hline & $p<0.001$ & $\mathrm{p}<0.02$ & ns & \\
\hline \multicolumn{5}{|l|}{$\mathrm{ARI}^{*}$} \\
\hline Yes & 23.3 & 35.9 & 15.2 & 1045 \\
\hline \multirow[t]{2}{*}{ No } & 18.8 & 31.3 & 12.2 & 1711 \\
\hline & $p<0.005$ & $\mathrm{p}<0.02$ & $p<0.05$ & \\
\hline \multicolumn{5}{|c|}{ AGE GROUP } \\
\hline $3-5 \mathrm{mo}$ & 3.9 & 3.9 & 2.0 & 152 \\
\hline $6-11 \mathrm{mo}$ & 10.4 & 17.2 & 8.2 & 297 \\
\hline $12-17 \mathrm{mo}$ & 21.4 & 31.6 & 16.0 & 262 \\
\hline $18-23 \mathrm{mo}$ & 21.0 & 29.1 & 17.2 & 291 \\
\hline $24-29 \mathrm{mo}$ & -22.8 & 40.9 & 11.5 & 298 \\
\hline $30-35 \mathrm{mo}$ & 18.2 & 32.9 & 14.7 & 286 \\
\hline $36-41 \mathrm{mo}$ & 22.4 & 41.7 & 14.0 & 290 \\
\hline $42-47 \mathrm{mo}$ & 23.7 & 37.1 & 12.4 & 295 \\
\hline $48-53 \mathrm{mo}$ & 27.2 & 39.9 & 13.8 & 327 \\
\hline \multirow[t]{2}{*}{$54-59$ mo } & 24.6 & 40.6 & 19.1 & 284 \\
\hline & $p<0.001$ & $\mathrm{p}<0.001$ & $p<0.001$ & \\
\hline
\end{tabular}

${ }^{*} \mathrm{ARI}=$ Acute respiratory illness 
similar result for chronic undernutrition was observed for children whose birth weight was unknown suggests that these children may also have been born small.

Having diarrhoea, fever, or an acute respiratory infection. in the preceding two weeks was associated with chronic undernutrition, suggesting that these children may suffer from repeated illnesses. Acute Respiratory Illness (ARI) was also associated with acute undernutrition.

\section{Age-specific patterns of undernutrition}

As with the NHS1, NHS2, and NHS3, the NHS4 shows that there was a clear age-specific pattern in the prevalence of undernutrition. Among infants age 3 to 5 months, the prevalence of stunting, underweight, and wasting was 4, 4, and 2 percent, respectively (Table 4). After 6 months of age, the prevalence of undernutrition increased rapidly and between the age of 12 and 17 months of age, 21,32 , and 16 percent of child ren were stunted, underweight, and wasted, respectively, after which the prevalence of stunting levels out while that for underweight increased and levels off at around 40 percent and that for wasting declines a little. These results indicate that the critical period of nutritional vulnerability for children throughout Sri Lanka is during the first 18 months of life.

\section{Nutrition status between 1993 and 1995}

As Table 5 shows, there appears to be no change in the nutrition status of children between 3 and 60 months of age between August/September 1993 and July/August 1995.

Table 5

Prevalence of stunting, underweight, and wasting in the different NHS

\begin{tabular}{lcccc}
\hline & Stunted & Underweight & Wasted & No. \\
DATE & & & & \\
Aug/Sep 1993 & - & 34.7 & - & 2618 \\
Mar/Apr 1994 & 20.9 & 34.3 & 13.4 & 1959 \\
Oct/Dec 1994 & 20.8 & 31.4 & 12.1 & 1547 \\
Jul/Aug 1995 & 20.4 & 32.9 & 13.4 & 2782
\end{tabular}

Table 6

Mean and standard deviation height, weight, and body mass index (BMI) of mothers' by province, sector, and age group

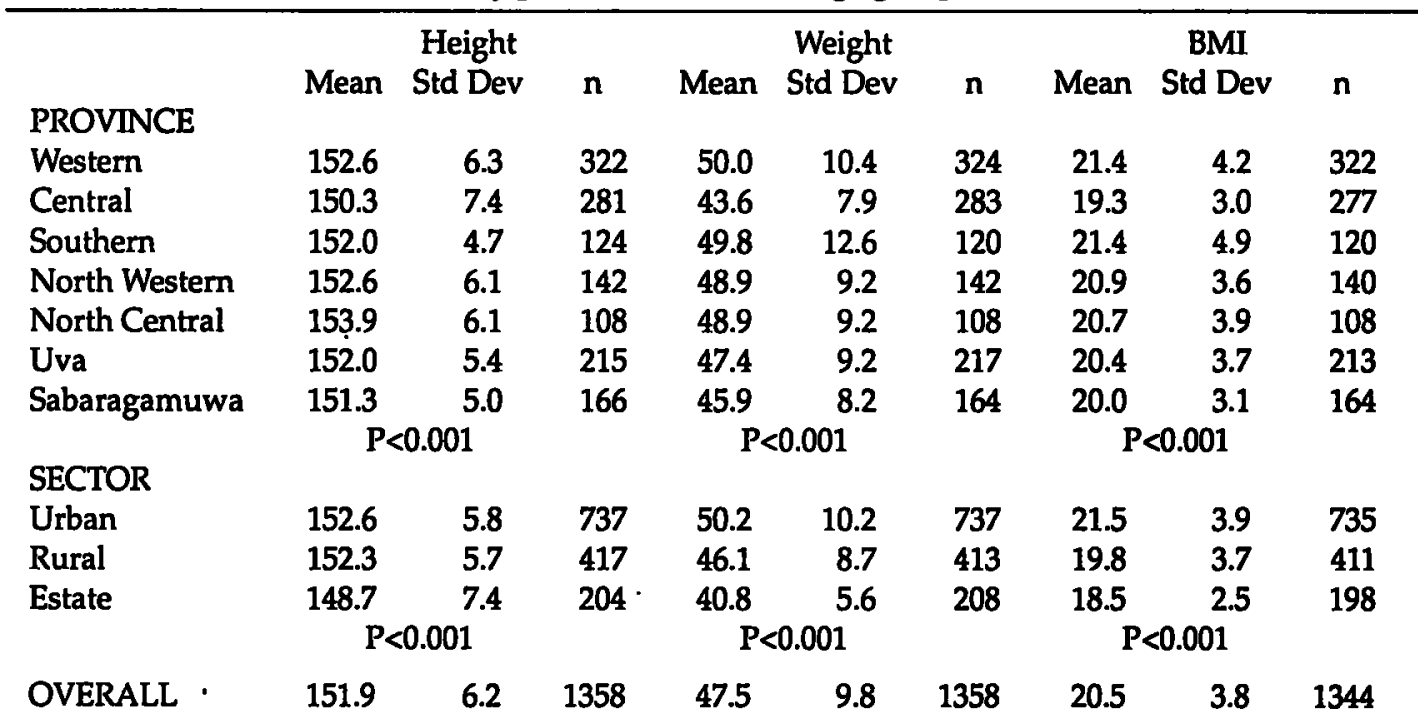




\section{Nutritional status of adults}

Table 6 shows the mean height, weight, and body mass index (BMI, wt $/ \mathrm{ht}^{2}$ ) of non-pregnant mothers with children under the age of five years. Overall, non-pregnant mothers were 152 $\mathrm{cm}$ tall and weighed $47.5 \mathrm{~kg}$. Mothers living in the Central province and in the estate areas tended to be shorter and, along with mothers in the Sabaragamuwa province, lighter than mothers living elsewhere.

The body mass index (BMI) is used to assess thinness or obesity in adults. A BMI below 18.5 has been defined as chronic energy deficiency and that below 16 as severe chronic energy deficiency (3). In contrast, a BMI above 25 indicates overweight and that over 30 obesity. Table 6 shows that the average BMI for mothers with children under five years is 20 and BMI tends to be lower in the Central province and in the estate areas than elsewhere.

Anthropometric data were available for 92 percent of fathers. Overall, fathers of children under the age of five years were $164 \mathrm{~cm}$ tall and weighed $55 \mathrm{~kg}$ (Table 7). As with mothers, there were both provincial and sector differences in heights; fathers in the Central province and in the estate areas were shorter and lighter than elsewhere. Overall, BMI for fathers was similar to that for mothers.

Table 8 shows that a greater proportion of mothers were severely or moderately undernourished compared with fathers, while the opposite was true for being mildly undernourished.

Tables 8 and 9 show the prevalence of undernutrition, defined as BMI below 18.5, of non-pregnant mothers and fathers by province, sector and income quartiles. Undernutrition was associated with province, sector, and income quartile. The prevalence of undernutrition was higher in the Central province for both mothers and fathers, although the levels for undernourished fathers in the Southern and North Central provinces was higher than in the other provinces. The prevalence of undernutrition was higher in rural (43 percent for both mothers and fathers) than in urban ones (21. percent for mothers, 28 percent for fathers) and higher in estate areas (59 percent for mothers and 50 percent for fathers) than in rural areas for both mothers and fathers. Among both

Table 7

Mean and standard deviation height, weight, and body mass index of fathers' by province, sector, and age group

\begin{tabular}{|c|c|c|c|c|c|c|c|c|c|}
\hline \multirow[b]{2}{*}{ PROVINCE } & \multicolumn{3}{|c|}{ Height } & \multicolumn{3}{|c|}{ Weight } & \multicolumn{3}{|c|}{ BMI } \\
\hline & Mean & Std Dev & $\mathrm{n}$ & Mean & Std Dev & $\mathbf{n}$ & Mean & Std Dev & n \\
\hline Western & 164.9 & 6.8 & 324 & 58.2 & 13.1 & 324 & 21.3 & 4.7 & 324 \\
\hline Central & 162.2 & 8.4 & 282 & 50.9 & 9.1 & 282 & 19.2 & 2.9 & 280 \\
\hline Southern & 163.8 & 6.3 & 124 & 52.7 & 9.9 & 124 & 19.5 & 3.1 & 124 \\
\hline North Western & 165.7 & 6.3 & 144 & 59.1 & 11.4 & 144 & 21.4 & 3.5 & 144 \\
\hline North Central & 167.4 & 6.7 & 107 & 56.2 & 10.1 & 107 & 20.0 & 3.5 & 107 \\
\hline Uva & 164.0 & 5.8 & 148 & 55.1 & 9.5 & 152 & 20.5 & 3.3 & 146 \\
\hline \multirow[t]{2}{*}{ Sabaragamuwa } & 164.1 & 7.3 & 165 & 53.3 & 8.9 & 167 & 19.6 & 2.8 & 165 \\
\hline & \multicolumn{2}{|c|}{$P<0.001$} & & \multicolumn{2}{|c|}{$P<0.001$} & & \multicolumn{2}{|c|}{$P<0.001$} & \\
\hline SECTOR & & & & & & & & & \\
\hline Urban & 165.4 & 6.7 & 669 & 58.3 & 12.0 & 673 & 21.2 & 4.1 & 669 \\
\hline Rural & 164.4 & 6.2 & 412 & 53.1 & 9.2 & 414 & 19.6 & 3.0 & 412 \\
\hline \multirow[t]{2}{*}{ Estate } & 160.6 & 8.9 & 213 & 48.4 & 6.6 & 213 & 18.7 & 2.4 & 209 \\
\hline & \multicolumn{2}{|c|}{$P<0.001$} & & \multicolumn{2}{|c|}{$P<0.001$} & & \multicolumn{2}{|c|}{$P<0.001$} & \\
\hline OVERALL & 164.3 & 7.1 & 1294 & 55.0 & 11.1 & 1300 & 20.3 & 3.7 & 1290 \\
\hline
\end{tabular}


mothers and fathers, higher levels of undernutrition were, as expected, positively associated with decreasing income quartile. The big difference, however, is between the third and highest income quartile. These figures should be compared with data obtained from a group of sportsmen and sportswomen (4). Only $\mathbf{5 3 \%}$ women and $77.9 \%$ of the men could be considered normal. The value for Resting Metabolic Rate used by Ferro-Luzzi et al (3) in arriving at a cut-off point of $\mathbf{1 8 . 5}$ for BMI, may be too high for Sri Lankans (4).

Table 8

Distribution and cumulative distribution of BMI for mothers and fathers

\begin{tabular}{lrrrrrrr}
\hline & \multicolumn{3}{c}{$\begin{array}{c}\text { Mother } \\
\text { Cumulative } \\
\text { Percent }\end{array}$} & $n$ & Percent & \multicolumn{3}{c}{$\begin{array}{c}\text { Father } \\
\text { Cumulative } \\
\text { Percent }\end{array}$} & $n$ \\
NUTRITION STATUS & Percent & & & & & & \\
Severe undernutrition & 8.8 & 8.8 & 118 & 5.4 & 5.4 & 69 \\
Moderate undernutrition & 9.8 & 18.6 & 132 & 8.9 & 14.2 & 114 \\
Mild undernutrition & 14.8 & 33.4 & 199 & 22.0 & 36.2 & 283 \\
Normal & 53.4 & 85.7 & 703 & 54.0 & 90.2 & 696 \\
Mild overnutrition & 8.2 & 93.9 & 110 & 6.5 & 96.7 & 84 \\
Mild overnutrition & 3.4 & 97.3 & 46 & 1.9 & 98.6 & 24 \\
Severe overnutrition & 1.2 & 98.5 & 16 & .6 & 99.2 & 8 \\
Obese & 1.5 & 100.0 & 20 & .8 & 100.0 & 10 \\
& 100.0 & & 1344 & 100.0 & & 1288
\end{tabular}

Table 9

Percentage of mothers and fathers who were undernourished, based on body mass index, by background factors

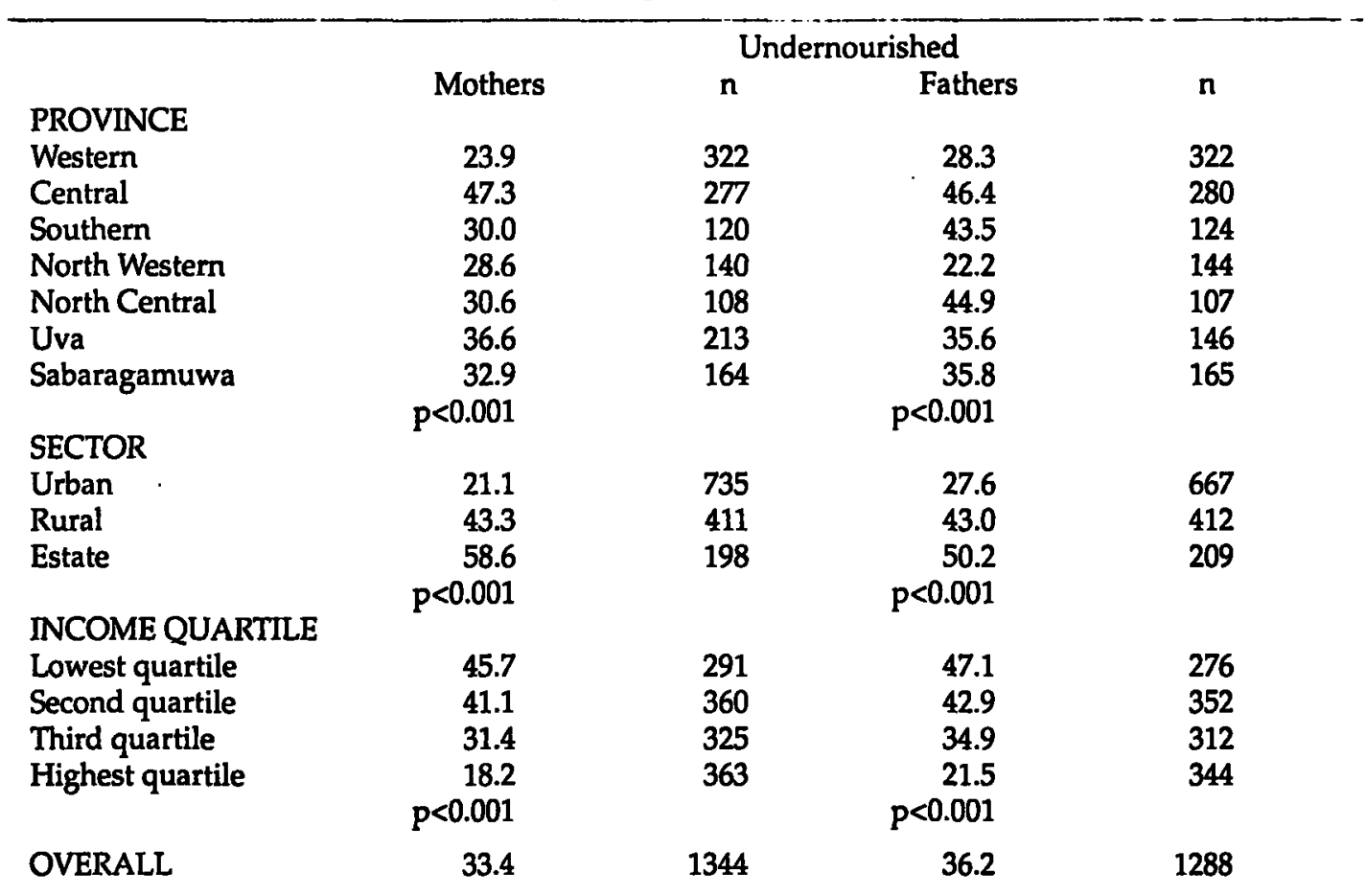


Compared with NHS3, conduced in October/December 1994, there has been a negligible decline in undernutrition among mothers ( 33 percent versus 35 percent) and a small decline in that among fathers ( 36 percent versus 42 percent). It is important to note that the data for fathers in NHS3 were much more limited in that many fathers were absent; thus, futher analyses will determine whether the difference in the prevalence of undernutrition between NHS3 and NHS4 is statistically significant.

\section{Night Blindness}

Mothers were questioned about nightblindness in their children. Among children over the age of two years 0.5 percent were nightblind, suggesting that clinical vitamin A deficiency is not a public health problem on the island. Nightblindness was also very low in NHS 3 (October/December 1994).

Iodized salt

Eighteen percent of mothers in Sri Lanka did not know about iodized salt, 39 percent knew but

Table 10

Percentage distribution of knowledge and use of iodized salt by households according to province and sector

\begin{tabular}{lccccccc}
\hline & $\begin{array}{c}\text { Iodized Salt } \\
\text { Don't know } \\
\text { don't use }\end{array}$ & $\begin{array}{c}\text { Know but } \\
\text { don't use }\end{array}$ & $\begin{array}{c}\text { Know and } \\
\text { use }\end{array}$ & Total & n & \\
PROVINCE & 16.3 & 33.7 & 49.9 & 100.0 & 569 & \\
Western & 24.4 & 34.5 & 41.2 & 100.0 & 476 & \\
Central & 8.5 & 27.5 & 64.0 & 100.0 & 189 & \\
Southern & 12.2 & 48.6 & 39.2 & 100.0 & 288 & \\
North Western & 27.9 & 41.9 & 30.2 & 100.0 & 265 & \\
North Central & 15.7 & 42.0 & 42.3 & 100.0 & 281 & \\
Uva & 14.6 & 47.1 & 38.3 & 100.0 & 329 & p $<0.001$ \\
Sabaragamuwa & & & & & & \\
SECTOR & 12.8 & 38.1 & 49.2 & 100.0 & 1184 & \\
Urban & 16.5 & 39.4 & 44.0 & 100.0 & 865 & \\
Rural & 37.9 & 40.2 & 21.8 & 100.0 & 348 & p $<0.001$ \\
Estate & 17.8 & 38.9 & 43.3 & 100.0 & 2397 & \\
OVERALL & & & & &
\end{tabular}

Table 11

Percentage distribution of knowledge and use of iodized salt by households according to province and sector

\begin{tabular}{lrrrrrrl}
\hline & $\begin{array}{c}\text { Avoid } \\
\text { Goitre }\end{array}$ & $\begin{array}{c}\text { Good for } \\
\text { health }\end{array}$ & Other & Total & $\mathrm{n}$ & \\
PROVINCE & 44.1 & 48.3 & 7.7 & 100.0 & 286 & \\
Western & 63.9 & 30.4 & 5.7 & 100.0 & 194 & \\
Central & 45.8 & 43.2 & 11.0 & 100.0 & 118 & \\
Southern & 10.6 & 73.5 & 15.9 & 100.0 & 113 & \\
North Western & 6.1 & 76.8 & 17.1 & 100.0 & 82 & \\
North Central & 58.0 & 36.1 & 5.9 & 100.0 & 119 & \\
Uva & 54.8 & 31.7 & 13.5 & 100.0 & 126 & $\mathrm{p}<0.001$ \\
Sabaragamuwa & & & & & & \\
SECTOR & 41.8 & 50.1 & 8.1 & 100.0 & 581 & \\
Urban & 48.6 & 38.8 & 12.6 & 100.0 & 381 & \\
Rural & 40.8 & 50.0 & 9.2 & 100.0 & 76 & p $<0.001$ \\
Estate & 44.2 & 46.0 & 9.8 & 100.0 & 1038 & \\
OVERALL & & & & & & \\
& & & & & The Ceylon Journal of Medical Science
\end{tabular}


did not use iodized salt, and 43 percent both knew and used iodized salt (Table 10). Fewer mothers in the Central and North Central provinces and in estate areas knew about would be maintained. Despite this, over onehalf of households using iodized salt in the North Central Province continue to wash the salt before using it, which means that much of

Table 12

Percentage distribution of form in which salt is used according to province and sector

\begin{tabular}{lrrrr}
\hline & $\begin{array}{c}\text { Wash } \\
\text { first }\end{array}$ & $\begin{array}{c}\text { Use as } \\
\text { it is }\end{array}$ & Total & $\mathrm{n}$ \\
PROVINCE & 14.4 & 85.6 & 100.0 & 285 \\
Western & 11.3 & 88.7 & 100.0 & 195 \\
Central & 15.7 & 84.3 & 100.0 & 121 \\
Southern & 0 & 100.0 & 100.0 & 113 \\
North Western & 53.7 & 46.3 & 100.0 & 82 \\
North Central & 7.6 & 92.4 & 100.0 & 119 \\
Uva & 13.2 & 86.8 & 100.0 & 121 \\
Sabaragamuwa & & & & \\
& 12.8 & 87.2 & 100.0 & 579 \\
SECTOR & 13.1 & 86.9 & 100.0 & 381 \\
Urban & 35.5 & 64.5 & 100.0 & 76 \\
Rural & & & & \\
Estate & 14.6 & 85.4 & 100.0 & 1036 \\
& & &
\end{tabular}

iodized salt, while more mothers in the Southern province and in urban areas knew and used iodized salt.

Among the mothers who used iodized salt, 44 percent did so to prevent goitre, a further 46 percent did so for health reasons although they did not specify goitre, and the remainder cited other reasons (Table 11). In NHS3 (October/December 1994) 50 percent cited to prevent goitre, 38 percent stated iodized salt is good for health, and 12 percent gave other reasons. The difference in the results maybe reflecting that mothers are becoming more aware of the more widespread benefits of iodized salt besides prevention of goitre.

Mothers in the North Western and North Central provinces appear to be more aware of the broader need for iodine, in that they were more likely to cite health reasons, while mothers in the other provinces were more likely to state that iodized salt prevent goitre.

Table 12 shows that the majority of households (85 percent) did not wash salt before using it; thus, ensuring the beneficial effects of the salt the iodine maybe lost. These households were likely to be those on the estates.

\section{Further analyses}

There are a wealth of data on factors associated with the nutrition and health of children that have not been presented in the NHS preliminary reports. The data from all four surveys will be merged and in depth analyses done to identify some of the critical factors predisposing Sri Lankan infants and young children to undernutrition so early in life. The results of these analyses will enable recommendations to be put forward for policy decisions.

\section{Acknowledgements}

Dr. Chandrani Piyasena of the Medical Research Institute trained the persons who took the antropometric measurements in all four surveys. Selection of nurses and their training for estimation of haemoglobin in third survey was also her responsibility. Funding for the survey was from USAID Colombo. 


\section{References}

1. Nestel P S, Ratnayake R M K. Nutrition and health status of children: results of the first nutrition and health survey. Battaramulla, Nutrition and Poverty Alleviation Division, Ministry of Policy Planning and Implementation, 1993.

2. Ratnayake R M K, Weerasinghe S. Sri Lanka Nutritional Status Survey, 1988/89. Ceylon Journal of Medical Science 1990; 33:31-45.
3. Ferro-Luzzi A, James W P J, Waterlow J C. The definition of chronic energy deficiency. Report of a working partly of the International Dietary Consultative Group. European Journal of Clinical Nutrition 1988; 4:969-981.

4. Wikramanayake T W, Dassanayake J, Wikramanayake $G \mathrm{~N}$, Amarasinghe $S$. Anthropometry of Sri Lankan sportsmen and sportswomen, with special reference to Body Mass Index. Ceylon Journal of Medical Science 1991; 34:15-32. 